\title{
Review of American Notary System - New Developments, Challenges and Its Coping Strategy
}

\author{
Rongxin Zeng ${ }^{1}$ \\ ${ }^{1}$ School of Law, Jiangxi University of Finance and Economics, Nanchang, China \\ Correspondence: Rongxin Zeng, School of Law, Jiangxi University of Finance and Economics, China. E-mail: \\ zrx0501@gmail.com
}

Received: October 22, 2013 Accepted: November 18, 2013 Online Published: November 29, 2013

doi:10.5539/jpl.v6n4p121

URL: http://dx.doi.org/10.5539/jpl.v6n4p121

\begin{abstract}
Back in 2010, President Barrack Obama vetoed a bill -- Interstate Recognition of Notarizations Act (know as H.R.3808) - that requires courts and other entities to recognize licensed notaries. The notaries, from all states, create a lot of attention towards a topic rarely discussed in the public domain. Despite the fact that most individuals view the notarization process as a formality, it has significance on the states governance. State government officials in charge of overseeing the notary commission realize the gravity and significance of this function. Notaries have a variety of rules in various governments. They establish the bonafide of signatures for protecting transactions from forgery and fraud cases. The presence of a notary's signature bolsters a document's authenticity. The notary system, however, faces a variety of challenges in meeting its obligations. Issues rise in the coordination of transaction security and contract freedom, transaction security and efficiency, and the incorporation of information and communications technology (ICT) and internet into the notary system. The research paper explores the problems in high detail. It focuses on the state of the notary system, previous research, challenges, effects and means of improving the efficiency of the system, through adjustments.
\end{abstract}

Keywords: veto, entities, notary, bonafide, authenticity, notary law

\section{Introduction}

A notary's responsibilities are equivalent to those of a lawyer; to some extent. A notary is a legally-trained individual; he/she receives a license, from the state, to carry out a variety of legal duties. There are slight variations in a notary's responsibilities; this depends on the legal provisions of the state where he/she works. According to the Colorado Secretary of State (2012), a notary is an authenticator, verifier, and person of integrity; he/she receives appointment and commissioning to seal documents. He/she is a public servant, impartial agent for the state, and public recorder of acts. In other words, a notary can be considered an official, unbiased and disinterested witness in the signing of documents.

What then is the notarization process? This is the use of a government-approved individual in witnessing another individual's signature, and attesting to it; this occurs through the provision of a signature and seal on the signed document (Greenwood, 2013).

\section{General Rules of American Notary System}

\subsection{Principal Functions of the American Notary}

Citizens in civil law jurisdictions, worldwide, require notarial services to execute agreements. This has gone on for centuries (New Orleans Notarial Archives, 2011). Notary law allows individuals to enter into contracts. The contracts serve a variety of purposes such as; land purchase, money borrowing, collateral pledges, will preparation, marriages, partnership formation, execution of building contracts and child adoption. The law provides a reliable and clear framework for the conduction of legal businesses. It outlines a process for the individual to carry out legal transactions. Through its efficiency, it ensures protection of the sanctity of contracts and societal stability.

A notary has a variety of functions. According to the law, he has the authorization to perform six significant duties. These include: taking acknowledgments, administering affirmations and oaths, solemnizing marriages, attesting to photocopies of various documents, certification of the contents of a safe-deposit box, and verification of vehicle identification numbers (Florida Government, 2013). 


\subsubsection{Oaths and Acknowledgments}

A notary's work does not just involve the witnessing of a signature and identity verification. During the notarization of a signature, there are two principal official actions involved; taking an acknowledgement from the document signer and administering an oath. During the acknowledgement, the individual must be physically present, and declare that he/she is signing the document voluntarily. It is the notary's responsibility to ensure the individual understands and signs the document voluntarily. In case of doubts on those terms, the individual should be referred to an attorney for legal advice. Some of the documents requiring an acknowledgement include; mortgages, deeds, powers of attorney and contracts. In the case of motor vehicle titles, the power of attorney does not apply.

The administration of an oath involves a verbal exchange between individuals and the notary. The individual admits that he/she is taking an oath. The oath is similar to that taken in court. On receiving an affirmation response from the individual, the notary completes a notarial certificate; this shows that the oath an affirmation occurred. Under no circumstances should a notary advise the individual on which notarial act is appropriate, or contents of the document. An example of a sworn statement requiring an oath is an affidavit.

When a witness gives a testimony under oath or affirmation, it is a deposition. It occurs outside the court; lawyers ask the witness oral questions. A notary has the authority of administering an oath for deposition. The deponent's physical presence is crucial; this facilitates the identification. However, the notary cannot actively participate in witness questioning.

\subsubsection{Attesting to Photocopies}

There are situations requiring photocopies of vital documents. It is the notary's responsibility to attest to the authenticity of those copies. According to the notary law, notaries only attest photocopies under conditions. First and foremost, the document must be an original one; a photocopy or another certified copy cannot be used. Subsequently, the document must not be a public record; if the document can be retrieved from the official source, it should be rejected by the notary. Last but not least, the photocopying process must be supervised by the notary. Only then should the notary prepare a notarial certificate. The certificate can be stamped and written on the back of the photocopy, or attached as a separate document. There are several public records whose copies cannot be attested by a notary. They include; marriage certificate, birth certificate, death certificate, document files in court proceedings, certificate of naturalization or citizenship, documents recorded by the Clerk of the court, student records, public records maintained in government offices, filed federal and state income tax forms, and professional licenses issued by the state.

Documents that can be photocopied from their originals and attested by the notary include; driver's license, vehicle title, diploma, social security card, medical records, bill of sale, U.S. passport, contract, lease, resident alien card, and personal letters.

\subsubsection{Solemnizing Marriages}

This role is only efficient in three U.S. states. The notary can perform the act only within the geographical boundaries of the state. Before the procedure, the couple must acquire a valid marriage license from the court judge or clerk; this is the presented to the notary. The notary performs the simple civil marriage ceremony. The vows by both individuals must reflect their desire to make the act a legally binding commitment. The notary makes a certificate on the marriage license and returns it to the office of the judge or clerk circuit court; this occurs within ten days of the marriage. The notary can perform this duty even to friends and family. He/she has a responsibility of ensuring the license and identification $\mathrm{f}$ the bride and groom are valid. Apart from notary, two more witnesses must sign the marriage certificate; this provides proof of marriage in the future.

\subsubsection{Verifying a Vehicle Identification Number}

In some states, applying for a title on a used motor vehicle, for the first time requires a sworn statement. The owner must sign a sworn statement; this shows that the VIN and odometer reading on the motor vehicle are correct. Certification of the VIN involves a physical inspection of the vehicle. The notary carries out the certification of the information; this occurs through the use of a form from the department of Highway Safety and Motor Vehicles. The notary ensures the information on the sworn statement is complete before notarization. This is the first section which includes a notarial certificate. The second section verifies the physical inspection. The notary includes a date, signature, date and notary seal. 


\subsubsection{Certifying the Contents of a Safe-Deposit Box}

In Florid, if the rental fee is overdue, a financial institution can open a safe-deposit box. A public notary has the authority and must be present during the process. His/her central role is the formation of an inventory of the vault's contents, and prepare a certificate of the opening. He/she must not be related to the financial institution in any way; the notary must not be an employee, officer, stockholder, or director of the institution. The certificate of opening contains details like; date of opening, dame of the lessee, and list of contents. All the information should be recorded and stored for future use.

\subsection{Prohibitions for Notarial Acts}

There are cases when notaries cannot perform their duties. First and foremost, the person whose signature is being notarized, must be present during the process. If the individual is not present, the signature should not be notarized. This, however, changed with technological advancements. E-notarization does not require the physical presence of an individual, just the verified documentation and identity. Subsequently, an incomplete document cannot be notarized. The notarization process verifies that all information provided is true and valid. Incomplete documents allow for forgery and fraud. The notary must go through the document, and ensure the completion of all sections. Only then can he/she proceed with the process.

Mental incapacitation of the individual prohibits the signing of documents. One of the requirements of the signature notarization is to ensure the individual understands the contents of the document and signs it voluntarily. An individual with mental incapacitation lacks the objectivity and ability to comprehend contents of the document. The notary must know whether the person is mentally healthy, or not. Personal relations with the individual whose signature is to be notarized prevents the notary from performing his duties (Lilly, 2013). In this case, the individual may be the notary's son, daughter, spouse, mother, father, or other close relation. It is likely to influence the notary's role; he/she may overlook areas of concern during the verification of the contents of the document.

In a case where the notary has a financial interest in the transaction, he cannot carry out the process. He/she cannot provide legal advice, to the individual, unless he/she is a legal attorney. Any other prohibited activities must be avoided. These include: the notarization of his/her own signature, charging for more than $\$ 10$ per notarial service and $\$ 20$ for solemnizing a marriage, notarizing a signature without adequate evidence of identification, using a different name or signature, signing a blank certificate of acknowledgement or affidavit, and altering written documents.

\section{Comparison of American Notary System and Latin Notary System}

In the US, most notaries are common law officers. Their roles are limited and different from those of civil law notaries. The two groups of notaries exhibit differences. There relate to the differences in the legal systems; civil law legal system and common law legal system.

\subsection{Civil Law Notary System}

The roots of the modern Civil law notary system (also known as Latin notary system) are to be found in the values of humanism, of the search of justice and protection of the weakest subjects. It applies in most countries; mainly in most parts of South America. State-appointed notaries, in such countries, have the responsibility of providing legal security for individuals entering into contracts. It applies to cases of; family, inheritance, property, company law, commercial law and so on (Couzens, 2013). The notaries receive high training, in comparison to the common law notaries. They provide a full range of services and they are important players of these legal systems.

\subsection{Common Law Notary System}

This system operates according to the laws of the commonwealth countries. It also applies in all states of USA, with exception to Louisiana (Couzens, 2013). A common law notary has the responsibility of identifying document signers, administering oaths, taking acknowledgements and executing jurats. Due to their limited roles, they cannot draft legal documents for individuals. Other activities they cannot do include: assisting document signers in understanding the document's content, and providing advice (Colorado Revised Statutes, 2013).

The evident differences between the legal systems and their provisions for notary services causes the confusion. Many individuals fail to comprehend the unique duties of each notary. The differences arise due to a variety of reasons. One of these is challenges facing the notary system. Problems of confidentiality and security issues pose a need for improved transactions. Criminals may pose as notaries and perform their duties. The common law 
notary's duties can easily be done by fraudsters. Thus, the use of highly trained and qualified civil law notaries proves efficient; they can carry out crucial and confidential legal transactions.

\section{Conflict and Coordination of the Intervention of Notary and Some Legal Values}

\subsection{Coordinating the Relationship between Contract Freedom and Transaction Security}

The notarization of a signature is a crucial process. It is necessary to ensure it occurs in an efficient and secure manner. The information should only be available to the relevant individuals. Notaries employ a variety of strategies to boost the security of this process. These strategies reduce the chances of criminal activities such as forgery, fraud or tampering with the signed document. In most cases, ensuring the security of the process limits the individual's freedom. The document signer may feel limited by the transaction security requirements. In its attempt to strengthen the transaction security, the notary system violates the liberty of parties.

The situation creates a significant challenge. There is a need to come up with strategies of balancing the two sides; the coordination of the relationship between contract freedom and transaction security. The notary should make the document signer aware of the rules and regulations of the process. This occurs before the process begins. The signer becomes aware of the expectations. He/she also learns about the notary's responsibilities, and his/her own. The notary must explain the security measures and why they are crucial. This helps the document signer in understanding the need for the measures. He/she understands why transaction security and confidentiality are crucial, during the process. It helps the signer in becoming more compliant. When the document signer understands the measures/ he/she works hard in an attempt to maintain them. Understanding the need for security, eliminates the feeling of limited freedom. On understanding the contents of the contract, the signer becomes ready to abide by them. The final signature shows the signer's willingness to stick to the document's provisions.

\subsection{Coordination the Relationship between the Transaction Security and Transaction Efficiency}

The notarization of a signature is a complex and detailed process. It consists of rules, regulations, documents and steps. The notary and document signer must ensure the process is complete before notarization. If not coordinated correctly, the process can take a long while. Challenges such as the acquisition of relevant documents, ensuring the signer's mental health, and identity verification may slow down the process. It results in a waste of time and financial resources. How can this be prevented? There is no way the process can be ignored. Transaction security is a crucial part of the notarization process. No matter how tedious the process is, the notary has the responsibility of ensuring the procedure goes according to legal provisions. He must take the signer through all the steps and eliminate any errors. On ensuring the authenticity of the documents and signer, the notarization can end (Pennsylvania Department of State, 2013).

The need to uphold transaction security, however, impedes the system's efficiency (Le Coq, 2011). It makes the process a hectic and time-consuming one. The problem can be solved through the use of advanced systems. The incorporation of technological advancements in the document and identity verification is likely to speed up the process. It also eliminates the need for the document signer's presence during the process. The use of ICT and the internet in notarization increases its efficiency. It shows that technology can help in the coordination of transaction security and transaction efficiency.

Economic analysis of the notarization process shows the cost of strategies; it provides insight into which strategies are cost-effective and fast (McAfee, 2007). It highlights means of maximizing on the use of ICT and internet; this means the internet can serve a variety of purposes. Some of the roles include; identity verification, document verification, signing and sealing, ensuring confidentiality and security, and tracking forgers and imposters, in the system. It saves on the costs on paper-based notarization processes. It also makes it easy for notary and document signers to get in contact and carry out transactions. It makes use of minimum resources in service provision (Le Coq, 2011).

\subsection{Effect of Information and Communication Technology and Internet on the Notary System}

One of the most notable changes in today's world is the development of ICT. The use of ICT and internet service cuts across various sectors and entities in the social, government, business, and legal world. The notary system suffers. As discussed earlier, the notarization process is a complicated one. It involves the witnessing of an individual's signature by a government-approved person. He/she attests to it through the signature and sealing of the signed document (Greenwood, 2013). Since the 2000 Election Signatures in Global and National Commerce Act, notaries receive authorization to incorporate electronic systems into their activities. It is a widely spread activity in US notaries. Notary now has the ability of using electronic signatures in performing various duties; this process evolves continuously. It involves the adoption of new procedures and standards. It aims at the 
regulation of the notarization process, and elimination of challenges (NASS, 2011). Some of the reforms include; Uniform Electronic Transactions Act, National E-Notarization Standards, Model Notary Act, Uniform Real Property Electronics Recording Act, and Revised Uniform Law on Notarial Acts.

It can be explained in a contextual aspect. Williamson requires the notarization of a digital document. He acquires the service of a notary online. In order to notarize the document, Williamson types his name and date at the bottom of the document. He then sends it to the notary. On receiving the electronic document, the notary types his name, information on the seal, and date of notarization on the document. He then sends it back to Williamson. It is a basic electronic notarization process; this shows that e-notarization depicts the same essential elements, in comparison to the manual or paper-based notarizations. It is quick and effective; it applies in several states across USA. It eliminates challenges of costs and transportation.

\subsubsection{Challenges}

The benefits of electronic notarization brings about a variety of challenges. The challenges impede its ability and efficient performance. First and foremost, it does not require the physical presence of an individual. According to the notary law provision, the presence of an individual requiring notary services is crucial. The first step in the notarization process is the identification of individuals. It occurs through reference to significant proof of identity; these include the birth certificate, driving license and passport and other diplomatic documents. The individual's absence may increase cases of wrong details and fake documents. The notary may be less likely to notice any irregularities in the process. An individual's presence allows for the verification of and recording of proof of identity.

Subsequently, the lack of security in the process is a significant concern. Online transactions expose the existing paper process to cases of criminal exploitation and fraud. Most of the online processes lack safeguards. How is this risky? Criminals and fraudulent individuals can pose as notaries; they do this just by typing information on a screen. If potential clients are not keen, they are likely to be conned by the criminals. They end up paying unnecessary fees to the wrong individuals and acquire false documentation. It also results in the loss of properties. The complex nature of the internet makes it hard to trace these criminals, once they carry out transactions. It results in an increase of online fraud cases (Blibech \& Gabillon, 2006). This challenge leaves electronic notarization a step behind, in comparison to the paper-based notarization process. In the paper-based method, both parties must sign the notary and then stamp the document. It is efficient due to the difficulty in erasing, modifying or forging the notarizations; this is because the signatures and seals are on the paper's fiber. The verification tracks back to a government official who can be easily accessed to confirm its contents. An increase in fraud cases shows a need to increase online security.

Impersonation of a notary is likely to occur. During the online notarization process, an individual may pretend to be an actual public notary. $\mathrm{He} / \mathrm{she}$ can use the name and fake signature of a government notary, in duping unsuspecting individuals. It contributes to the case of fraud discussed in the above paragraph. The actual notary may be completely unaware of the misuse of his/her identity. It is because of the lack of advanced security systems online. Hackers are thus able to access the notary system's confidential information about various acts. How, then, can e-notarization process be performed if digital documents can be easily altered and forged.

\subsubsection{Response to Challenges Associated with ICT and Use of Notarization as Proof of Internet Infringement}

There are several challenges facing the incorporation of e-notarization into the system. Today, information technology is a key in enabling various government and business documents. Significant changes come with challenges; it raises a need to counter clever counterfeiters and forgers. Despite the fact that ICT use is dangerous, it can also be used productively.

First and foremost, challenges can be curbed through the use of enhanced security systems. These will facilitate a variety of mission-critical, high value, sensitive official transactions. It helps in the detection, prevention and prosecution of fraud cases. In e-notarization, the transaction evidence and a notary's potential testimony are deterrent to criminal activities. The evidence is formed and stored during the notarization process. All electronic notary processes must attempt to offer safeguards similar to paper-notarization processes. Through this, it increases its protective advantage. An efficient combination of technology, practices, policies, and standard lays the foundation for improvement of existing safeguards.

As noted, the lack of care exposes digital information to exploitative and fraudulent attacks. Through unique digital systems, the creative and complex types of fraud can be penetrated. These computer-based systems curb the vulnerabilities resulting from the use of electronic records and transactions in notarization. It is hard to detect whether a typed signature and information on word processors are forged, altered or deleted. This information 
can be easily manipulated. However, tampering with or counterfeiting the seal on an electronic document is detectible. Though not as easy as the detection of abrasions, surface inconsistencies, and subtle signature discrepancies in paper-based notarization, it can be detected. Forensic experts can use the notary seal's digital image; this adds to the e-notarization process. This method is efficient, but there is a need for improvement. There should be use of software with the ability to distinguish patterns in machine-readable data. Through this, errors and alterations can be identified. The software validate the data provided.

The software should be secure and inaccessible to fraudulent individuals. They should exist within a secure location where they can engage in the safe transfer of information. Such systems should be reliable, secure and usable; this is possible through a blend in the processes, technology and standards. Some of these systems include the; Secure Closed System. Secure Technology System, and Document Authentication Number (Greenwood, 2013).

\section{a. Secure Technology System}

In the USA, sophisticated technologies exist in the notarization process. Various parties see this as a solution to the evident security problem. Among these technologies is the Public Key Infrastructure. It is a complex system made up of cryptographic codes and service providers. The system ensures information scrambled by one code can be undone only by a specific corresponding code. The codes uniquely pair to avoid forgery. Every party received a digital certificate by a certification authority- trusted third party. It makes the identification process easy through the use of mathematical codes. It makes it easy for parties to identify the individuals they are dealing with online. It also ensures that any confidential and encrypted data from the party is not changed or corrupted, in any way. In short, this is a significant way of creating trusted and secure relationships online. Though highly effective, this software faces challenges of cost, complexity, relative immaturity, slowness, and infrastructure and security flaws. If these challenges were to be effectively countered, the software would take the notarization process a step ahead; technologically and in terms of security provision.

\section{b. Secure Closed System}

This is a straight-forward and simple approach in dealing with the security challenge. Entities using the notarization system can adopt secure software; these facilitate easier document workflow. The system allows all partners within the organization to access and use the software application. In order to make this possible, it employs a wide variety of information security tools; they perform notarization as an in-house activity. Among these is the application layer security. It has several widely-adopted software modules and protocols; these ensure confidentiality, authentication, and protection against tampering and other features. The software is efficient; this is because it can be tuned to incorporate existing software. This raises a need for all individuals to carry out particular functions. In order to further advance this software, more layers of personnel, procedures and controls can be incorporated; this ensures only the authorized notary carry out the activities.

\section{c. Document Authentication Number}

This is an efficient solution created by the state of Colorado; it enables state regulation of electronic notarization processes. How does this work? Each notary receives an 11-digit accounting number; it comes from the Secretary of States accounting system. It is a publicly accessible number; this means that it can be referenced and accessed by anyone. An individual can use the number to reach the notary online; this provides the verification of the notary's name, commission expiration date, commission number and other relevant information. Subsequently, the notaries receive multiple random numbers; these are confidential. The notary uses one of the numbers in the branding of discrete e-notarizations. A combined use of the DAN and random number creates the notary's electronic signature.

This system is simple and cost-effective. The information on all electronic notarization processes remain filed with the Secretary of State. It can be accessed and used even years after the transaction. In case a need for verification by a third party arises, it retrieves the information. Disputes may arise in relation to the notarized document. In such a case, the identification of the notary in question occurs. The information form the notarization process undergoes a review process to identify the complication. In such cases, the notary can provide a personal report and even testify on the facts of the transaction. This system improves the security of notarized documents. It occurs in a manner that would detect any future changes to the text in the document.

\section{d. Biometrics}

This is a secure technological approach in handling notarization processes. It involves the use of a system which measures an individual's physiological attributes. The attributes include; fingerprints, retina and voice patterns. The data acquired is digitalized and stored, as bar codes, within the computer's memory. In order to further 
secure this information, it can be encrypted; this prevents unauthorized access to the digital copy of biometric data. Its use in the notarization process requires a notary to apply a thumbprint; this is a signature during the process. Through further technological advancements, the notary and principal's signatures can be tied together; this associates the signed document with information on the notary seal. Digital images of the notary is a basis for facial recognition and validation.

The secure technology approaches increase the efficiency of the process. The SCS, for instance, provides unlimited flexibility. This is an advantage facilitated by the fact that various entities can customize and develop systems to meet their unique needs. The closed systems, on the other hand, focus on proprietary solutions. Various organizations such as Public Records Industry Association come up with standards to expand the number of parties allowed to join the closed system. These systems also provide public protection from fraud and direct accountability; this can be further enhanced through the harmonization of private and public sectors.

\section{Conclusion}

The notarization process is a complicated one. According to NASS (2011), the process varies in each state. A comprehensive coverage of the notary system consists of its; functions, unique and common practices, state notary regulations, qualifications for commissioned notaries, the notary seal, electronic notary practices, legal issues, challenges and possible solutions. Through a focus on the challenges, facing the notary system, the paper outlines the need for new strategies. The incorporation of enhanced and advanced strategies into the system goes a long way in improving efficiency. Despite the evident differences on notary systems in various states, there are notable similarities. Over the years, several statutes develop; this occurs in a bid to regulate and improve the problem it thus eliminates possible challenges. Notarization holds a significant role in the current governmental, societal and economic existence. Due to the gradual shift into the information age, and the use of advanced technologies, there is a need for new strategies in ensuring efficiency. The governments adopt comprehensive legal standards, models and uniform statutes controlling notarization, detailed rules, policies, and implementation strategies. Through efficient coordination, the regulations, statutes and other public policy mechanisms ensure effective notarization.

\section{Acknowledgment}

This research is supported by the fund of the Twelfth Five-year Plan of Social Science of Jiangxi Province, China (Number of the project: 11FX26). This support was greatly appreciated.

\section{References}

Bliebech, K., \& Gabillon, A. (2006). A New Digital Notary System. Retrieved September 9, 2013, from http://www.link.springer.com/chapter/10.1007\%2F978-3-642-01350-8_10\#page-1

Colorado Revised Statutes. (2013). Professions and Occupations General: Article 55 Notaries Public. Retrieved September 9, 2013, from http://www.sos.state.co.us/pubs/notary/files/article55.pdf

Colorado Secretary of State. (2012). Notary Handbook. Retrieved September 9, 2013, from http://www.sos.state. co.us/pubs/notary/files/notary_handbook.pdf

Couzens, J. (2013). Common and Civil Law. Thames Law Chamber. Retrieved September 9, 2013, from http:// www.aylesburynotary.co.uk/about-notaries-public/civil-and-common-law/

Florida Government. (2013). Duties of a Notary Public. Governor's Reference Manual for Notaries. Retrieved September 9, 2013, from http://www.flgov.com/wpcontent/uploads/notary/ref_manual11-22.pdf

Greenwood, D. J. (2013). Electronic Notarization. Massachusetts: National Notary Association. Retrieved September 9, 2013, from http://www.cdn.nationalnotary.org/Media/MIT-eNot0106.pdf

Le Coq, V. (2011). Notaries: A vector of economic inefficiency? Economy and Society, The Circle. Retrieved September 9, 2013, from http://lecercle.lesechos.fr/entreprisesmarches/services/221135197/notariat-vecteur-inefficacite-economique

Lilly, J. (2013). The Unlawful Notary. Last Word, Retrieved September 9, 2013, from http://www.lastwordedits. com/unlawfulnotary.pdf

McAfee, R. P. (2007). Introduction to Economic Analysis. California Institute of Technology. Retrieved September 9, 2013, from http://www.mcafee.cc/Introecon/IEA2007.pdf

National Association of Secretaries of State. (2011). Issues and Trends in State Notary Regulation: NASS report on state notarization policies and practices. Retrieved September 9, 2013, from http://www.wwnotary.com/ documents/nass-report-nota 
New Orleans Notarial Archives. (2011). Civil Law Notary. Retrieved September 9, 2013, from http://www.notarial- archives.org/civil.htm

Pennsylvania Department of State. (2013). What is a Notary Public? Retrieved September 9, 2013, from http://www.dos.state.pa.us/portal/server.pt/community/what_is_a_notary/12612

\section{Copyrights}

Copyright for this article is retained by the author(s), with first publication rights granted to the journal.

This is an open-access article distributed under the terms and conditions of the Creative Commons Attribution license (http://creativecommons.org/licenses/by/3.0/). 